\title{
Predicting treatment outcome in nocturnal enuresis
}

\author{
J B Devlin, C O’Cathain
}

\begin{abstract}
A presenting sample of 127 consecutive referrals to a community based enuresis clinic were evaluated after treatment with baseline behavioural recording and the enuresis alarm. Almost one in five became dry after baseline recording only while 81 of $96(84 \%)$ enuretics who used the alarm achieved the initial dryness criterion. Successful outcome was associated with the absence of adverse environmental factors and psychiatric disorders in the child. A logistic regression procedure enabled a risk score to be created so that successful outcome could be predicted. Psychiatric disorder in the child, family stress, and the degree of concern shown by the child emerged as the most important prognostic factors in the treatment of enuresis. The favourable success rates with baseline recording and the enuresis alarm confirm the role of conditioning treatment at the forefront of management of enuresis and the risk score allows outcome to be predicted for the first time.
\end{abstract}

Childhood nocturnal enuresis continues to be a common problem affecting approximately one in 10 children. ${ }^{12}$ It is associated with a wide variety of disorders in the child and socioenvironmental factors in the family. ${ }^{3-6}$ Even though enuresis causes considerable distress, many families either do not consult a doctor, or are unhappy with medical management of this problem. ${ }^{1}$

Treatment has revolved around pharmacotherapy or conditioning treatment such as the enuresis alarm. Tricyclic antidepressants are prescribed despite poor long term efficacy ${ }^{7-9}$ and warnings about the dangers of side effects. ${ }^{10-12}$ Antidiuretics (for example, desmopressin) are expensive yet no more effective than the alarm in achieving long term cure. ${ }^{13}$

The enuresis alarm has cure rates ranging from $30 \%-100 \%,{ }^{14}{ }^{15}$ but there are relatively few data concerning factors that may be associated with outcome. This study aims to evaluate management of nocturnal enuresis with the alarm, identify variables relating to successful outcome, and to create a risk score thereby enabling initial and long term outcomes to be predicted.

Eastern Health Board,
Dublin
J B Devlin
C O'Cathain
Correspondence to:
Dr J B Devlin,
Eastern Health Board,
Poplar Square, Naas,
Co Kildare, Ireland.
Accepted 14 June 1990

Subjects and methods

A presenting sample of 127 consecutive referrals to a community based enuresis clinic participated in the trial. Inclusion criteria were that the child was aged 6 to 18 years and wetting the bed at least twice a week. Exclusion criteria consisted of overt psychiatric disturbance requiring urgent referral to the child guidance service, moderate or greater mental handicap, and urological or neurological causes of incontinence. Equal numbers of referrals originated from paediatricians, general practitioners, and clinical medical officers with a smaller number from the child guidance service.

Clinics were arranged in local health centres and all children were seen initially by the medical officer (JBD), and review appointments were also seen by one of three specially trained nurses. Both the parent and child were given a structured interview to reduce interviewer bias. Information on (i) sociodemographic data, (ii) enuresis history, (iii) physical/psychiatric disorder, and (iv) family stress was elicited using a standardised chart.

(i) Sociodemographic data included age and sex of child, family size, birth order, place of residence (urban/rural), mother's and father's employment state, and social class based on an ordinal scale. ${ }^{16}$ Housing was rated as unsatisfactory if one or more of the following was present (a) no bathroom, (b) no indoor toilet, (c) enuretic child sharing a bedroom with more than one other child, (d) enuretic child sharing a bed, and (e) house in poor repair.

(ii) Enuresis was classified as primary if the child had never acquired nocturnal continence and secondary where the child was reliably dry at night for at least six months then started wetting again. Previous treatments were listed as was the presence of diurnal enuresis. The mother was asked separately about impact on the family regarding extra washing/ironing, smell, financial consequences, reactions of other siblings, emotional impact (anxiety, fear, anger, and annoyance), and finally her concern about the problem on an ordinal scale. The child was also seen separately and questioned about the effects of enuresis on his/her life (that is, at school, the smell in the bedroom, sleeping arrangements both at and away from home, who knows about it, what are his parents expectations, what he has done to control it, and whether he can imagine himself being dry) and then to summarise his/her distress on an ordinal scale.

(iii) Physical/psychiatric disorder: a history of serious physical illness or handicap or a stressful event in early childhood was recorded (that is, hospital admission, serious accident, death of a parent, etc). Developmental delay was ascertained by inquiring about developmental milestones (sitting unsupported by 9 months, ability 
to walk by 18 months, inability to say linked words by 2 years, etc). Children were psychologically screened using the Rutter parental rating (A scale) of their child's behaviour. ${ }^{17}$ Children categorised as deviant were referred for assessment to the child guidance service where the American Psychiatric Association Diagnostic and Statistical Manual III coding system for psychiatric illness was used. ${ }^{18}$

(iv) Family stress was coded similar to Dische et $\mathrm{al}^{19}$ and included (a) anomalous parental situation where the child was not living with both natural parents, (b) marital discord where one or both parents admitted discord and the marriage was associated with past or threatened separation, (c) other family disharmony, (d) serious handicap (parents or children), (e) parental mental illness), (f) death in the immediate family, and (g) serious financial problems ascertained by inquiring about difficulties paying for heating, food, electricity, and housing rental/mortgage.

Medical screening consisted of physical examination and a midstream urine for culture and analysis. At the initial visit parental cooperation was solicited in encouraging the child to assume full responsibility for the programme. The child's confidence was gained and the reasons for being at the clinic explained. This rapport with the child was continued at all stages with he/she answering questions and being actively involved in treatment. This included behavioural procedures such as cleanliness training (cleaning self, changing bed, and ensuring clothes are left for laundry), maintaining good personal hygiene, and daily bladder exercises (bladder stretching by restraining micturition at home during the day, stream interruption, and sphincter contractions). The child was given a chart to record the wetting frequency, time and size of the wet spot, and this behavioural recording acted as a baseline control period for later evaluation of treatment. This control period lasted eight weeks during which parents and child were seen on one occasion.

The child was then assessed for alarm suitability (wetting more than twice a week) and both parent and child were carefully instructed about alarm usage (Eastleigh SM 1 with or without Pex 2 booster) as described previously. ${ }^{20}$ Treatment was usually directed at the child with the mother instructed incidentally for supervision purposes. The child was advised to 'beat the buzzer' and treat the alarm like a friend. $\mathrm{He} / \mathrm{she}$ also took responsibility for alarm testing twice weekly and the alarm procedure was explored with the child at each visit. Close supervision was maintained by regular appointments (once or twice a month), written instructions for parents, a telephone advisory service, and speedy replacement of faulty equipment.

The alarm was used until a period of 21 consecutive dry nights was achieved but if a wet night occurred during the following three weeks, the alarm was used again. Any child who relapsed after this six week dry period was offered a further course of the alarm. Outcome was assessed at two, six, and 12 months and follow up was maintained at monthly intervals until he/she was dry for three months, then at one year by post or telephone.

All data was coded for computer processing and the SAS statistical package (SAS Institute) used for $\chi^{2}$ and stepwise logistic regression testing.

\section{Results}

\section{DESCRIPTIVE}

The mean age of the sample was 8.8 years (range 6-17) with a male:female ratio of 2:1. The social class distribution was socioeconomic group I $(n=14,11 \%)$, II $(n=18,14 \%)$, III $(n=14,11 \%)$, IV $(n=40,32 \%), V(n=32,25 \%)$, and VI $(n=9,7 \%)$. The unemployment rate among fathers was $30 \%$ and among mothers $70 \%$.

Enuresis was primary in $105(83 \%)$ and secondary in $22(17 \%)$ and most children $(83 \%)$ had nocturnal enuresis only with the remainder $(17 \%)$ also wetting during the day. Only two had a confirmed urinary tract infection but four had a urological abnormality. Twenty six $(20 \%)$ had a stressful event in early childhood consisting of a hospital admission due to physical illness $(n=21,17 \%)$, physical handicap $(n=2$, $2 \%)$, serious accident $(n=2,2 \%)$, and sexual abuse $(n=1,1 \%)$. A prior attendance at the child guidance clinic was noted in $27(21 \%)$ and comprised a reactive disorder $(\mathrm{n}=11,9 \%)$, learning problem $(n=7,6 \%)$, mental handicap $(n=4,3 \%)$, developmental delay $(n=2,2 \%)$, personality disorder $(n=2,2 \%)$ and psychosomatic disorder $(n=1,1 \%)$.

Altogether $52(41 \%)$ parents admitted to stress in the family. This was caused by financial difficulties $(n=13,10 \%)$, marital discord $(n=11,9 \%)$, unemployment $(n=7$, $6 \%$, death in the family $(n=6,5 \%)$, other family disharmony $(n=6,5 \%)$, serious illness in the family $(n=2,2 \%)$, and combinations of the above $(n=7,6 \%)$. A family history of psychiatric illness was recorded in $11(9 \%)$ of parents and adverse housing was coded in 23 $(18 \%)$ of families. Finally parents and children were asked to rate their concern about the bed wetting; this is recorded in table 1.

\section{OUTCOME OF TREATMENT}

From 127 consecutive referrals to the enuresis clinic, 22 children became dry on baseline behavioural recording alone and did not require the enuresis alarm. One of these had relapsed when followed up at 12 months. Eight children were lost to follow up after the initial visit and one child was referred for surgical management leaving 96 children who had a trial of the enuresis alarm. Of these $81(84 \%)$ achieved an initial successful outcome of 42 consecutive dry nights. The mean number of weeks to achieve

Table 1 Concern about enuresis

\begin{tabular}{lcl}
\hline Concern & $\begin{array}{l}\text { No (\%) of } \\
\text { parents }\end{array}$ & $\begin{array}{l}\text { No (\%) of } \\
\text { children }\end{array}$ \\
\hline None at all & $3(2)$ & $10(8)$ \\
A little & $15(12)$ & $33(26)$ \\
Moderate & $56(44)$ & $43(34)$ \\
A great deal & $53(42)$ & $41(32)$ \\
\hline
\end{tabular}


dryness with the alarm was $7 \cdot 3$ (range $1-26$ weeks). Eleven children (12\%) relapsed after the initial course of the alarm and required further treatment of which nine (82\%) achieved full dryness again and the remaining two achieved more than a $50 \%$ improvement in their wetting.

Outcome was also measured at fixed time intervals of two months (baseline recording only), six months (four months after alarm), and 12 months (10 months after alarm) and is outlined in table 2 . The cure rates in this table refer to children who continued to attend the clinic and if those lost to follow up are considered failures, the respective cure rates of the total number of children referred for treatment are (i) six months: all children $(95,75 \%)$, alarm group (73, 76\%), and (ii) 12 months: all children (75, $59 \%)$, alarm group (54, 56\%). Analysis at fixed

Table 2 Treatment outcome of 127 consecutive referrals. Results are number (\%) of those followed up

\begin{tabular}{|c|c|c|c|c|c|}
\hline \multirow[t]{2}{*}{ Outcome } & \multirow{2}{*}{$\begin{array}{l}2 \text { Months } \\
\text { (chart only) }\end{array}$} & \multicolumn{2}{|c|}{6 Months } & \multicolumn{2}{|c|}{12 Months } \\
\hline & & All & $\begin{array}{l}\text { Alarm } \\
\text { group }\end{array}$ & All & $\begin{array}{l}\text { Alarm } \\
\text { group }\end{array}$ \\
\hline $\begin{array}{l}\text { Cure } \\
\text { Failure } \\
>50 \% \text { improved } \\
\text { Lost/incomplete follow up }\end{array}$ & $\begin{array}{l}22(19) \\
96(81) \\
\frac{}{9}\end{array}$ & $\begin{array}{l}95(80) \\
15(13) \\
8(7) \\
9\end{array}$ & $\begin{array}{l}73(76) \\
15(16) \\
8(8) \\
0\end{array}$ & $\begin{array}{r}75(79) \\
11(12) \\
9 \quad(9) \\
32\end{array}$ & $\begin{array}{l}54(74) \\
10(14) \\
9(12) \\
23\end{array}$ \\
\hline
\end{tabular}

Table 3 Factors associated with outcome at six months

\begin{tabular}{|c|c|c|c|c|}
\hline Variable & Presence of variable & Cure rate (\%) & $x^{2}$ & p Value \\
\hline Stressful event (child) & $\begin{array}{l}\text { Present } \\
\text { Absent }\end{array}$ & $\begin{array}{l}64 \\
84\end{array}$ & $4 \cdot 8$ & $<0.05$ \\
\hline Psychiatric disorder (child) & $\begin{array}{l}\text { Present } \\
\text { Absent }\end{array}$ & $\begin{array}{l}58 \\
85\end{array}$ & $8 \cdot 5$ & $<0.01$ \\
\hline Family stress & $\begin{array}{l}\text { Present } \\
\text { Absent }\end{array}$ & $\begin{array}{l}70 \\
86\end{array}$ & $4 \cdot 7$ & $<0.05$ \\
\hline Parental concern & $\begin{array}{l}\text { None/little } \\
\text { Moderate/great }\end{array}$ & $\begin{array}{l}50 \\
84\end{array}$ & $10 \cdot 1$ & $<0.01$ \\
\hline Child's distress & $\begin{array}{l}\text { None/little } \\
\text { Moderate/great }\end{array}$ & $\begin{array}{l}47 \\
94\end{array}$ & $33 \cdot 6$ & $<0.01$ \\
\hline
\end{tabular}

Table 4 Factors associated with outcome at 12 months

\begin{tabular}{|c|c|c|c|c|}
\hline Variable & Presence of variable & Cure rate (\%) & $x^{2}$ & p Value \\
\hline Daytime wetting & $\begin{array}{l}\text { Often } \\
\text { Rarely } \\
\text { Never }\end{array}$ & $\begin{array}{r}0 \\
74 \\
82\end{array}$ & $8 \cdot 4$ & $<0.02$ \\
\hline Urological disorder & $\begin{array}{l}\text { Present } \\
\text { Absent }\end{array}$ & $\begin{array}{l}25 \\
81\end{array}$ & $7 \cdot 3$ & $<0.01$ \\
\hline Psychiatric disorder (child) & $\begin{array}{l}\text { Present } \\
\text { Absent }\end{array}$ & $\begin{array}{l}47 \\
86\end{array}$ & $12 \cdot 7$ & $<0.01$ \\
\hline Developmental delay & $\begin{array}{l}\text { Present } \\
\text { Absent }\end{array}$ & $\begin{array}{l}38 \\
83\end{array}$ & $9 \cdot 0$ & $<0.01$ \\
\hline Parental concern & $\begin{array}{l}\text { None/little } \\
\text { Moderate/great }\end{array}$ & $\begin{array}{l}50 \\
83\end{array}$ & 6.9 & $<0.01$ \\
\hline Child's distress & $\begin{array}{l}\text { None/little } \\
\text { Moderate/great }\end{array}$ & $\begin{array}{l}57 \\
88\end{array}$ & $11 \cdot 4$ & $<0.01$ \\
\hline
\end{tabular}

Table 5 Six month outcome and risk score

\begin{tabular}{lll}
\hline Variable & Score & Risk of failure \\
\hline No adverse variables & 0 & $5 \%$ \\
Family stress & 1 & Increased by $20 \%$ \\
Lack of child's distress & 2 & Doubled \\
Family stress and lack of child's distress & 3 & Quadrupled \\
\hline
\end{tabular}

Table 6 Twelve month outcome and risk score

\begin{tabular}{lcl}
\hline Variable & Score & Risk of failure \\
\hline No adverse variables & 0 & One in 10 \\
(a) Lack of child's distress & 3 & Increased by one quarter \\
(b) Developmental delay & 4 & Increased by one third \\
(c) Psychiatric disorder (child) & 4 & Increased by one third \\
(a+b) or $(a+c)$ & 7 & Inadrupled \\
$(b+c)$ & 8 & Increased 20-fold \\
$(a+b+c)$ & 11 & \\
\hline
\end{tabular}

time intervals also resulted in the cure rate at six months (four months after alarm) being less than the initial success rate because at this stage some children had relapsed while others had not yet achieved dryness but follow up at 12 months was considered an indicator of long term success.

\section{VARIABLES ASSOCIATED WITH OUTCOME}

The prognostic importance of several variables was examined for all children (that is, baseline recording group and alarm group) who persisted with treatment. For outcome purposes, children who achieved $>50 \%$ improvement in wetting but not full cure were considered to be failures. Variables found not to be associated with outcome included place of residence (urban/ rural), social class, employment state (mother or father), adverse housing, family size, child's age, sex and birth order, urinary tract infection, enuresis classification, and previous treatment for enuresis.

The significant factors associated with successful outcome at six and 12 months are shown in tables 3 and 4 respectively.

\section{RISK SCORE}

To predict outcome, a forward stepwise logistic regression procedure was performed for children attending the clinic at each of the fixed time intervals.

\section{Six months}

The variables significantly affecting outcome were stress in the family $(p=0.02)$ and the child's distress about the wetting $(p<0.01)$. When these two variables were removed from the regression equation the chance of a successful outcome at six months was $96 \%$. A risk score was then calculated from the logistic regression procedure and allows a rapid prediction of outcome at six months (table 5).

\section{Twelve months}

The variables reaching significance were psychiatric disorder in the child $(p<0.01)$, absence of child's concern about the wetting $(p=0.02)$, and developmental delay in the child $(p=0.03)$. Without these variables, the child has approximately a nine in 10 chance of being dry at 12 months. A risk score was also calculated for the 12 month outcome (table 6 ). These scores are additive so that if a child has all three adverse variables, the score is $3+4+4=11$ and the risk of treatment failure is 20 times that of a child without these variables.

\section{Discussion}

Bed wetting is essentially a benign condition but it may cause a considerable amount of distress for the child and worry for the parents. ${ }^{1}$ In this study the sample was inevitably selective as provisional admission was restricted to children older than 6 years of age and wetting at least twice a week. The pattern of referrals (secondary or tertiary) resulted in these children being considered 'difficult 
enuretics'. In addition, the characteristics of this study group of enuretics differed from those in a prevalence study carried out in the same area because unfavourable environmental factors were more likely to be present and a greater percentage of children tended to psychiatric disorder. ${ }^{2}$ These findings illustrate the principle that a presenting sample of consecutive referrals such as this is not entirely representative of the general population and is more likely to represent a more severe spectrum of a disease or condition.

At the enuresis clinic two methods of treatment were offered, namely baseline behavioural recording using a combination of a 'star chart' and behavioural procedures and the enuresis alarm. The cure rate of $19 \%$ using baseline recording only is in keeping with figures described elsewhere. ${ }^{21}$ This form of treatment increased the child's motivation, responsibility, and awareness of the problem and as this therapy was inexpensive and safe, it should be at the forefront of treatment.

The initial success rate of $84 \%$ with the alarm compares very favourably with other studies, ${ }^{14} 192022$ and may in part be due to close supervision and the child taking almost complete responsibility for the programme. The long term cure rate also remained high with almost four in five children dry one year after treatment. The fixed interval success rates refer to children who continued to attend the clinic and it is likely that many who ceased attending were failures, although Young and Morgan noted a significant percentage of non-attendance was due to the child achieving dryness or parental satisfaction with a reduction in wetting frequency. ${ }^{23}$ It was encouraging however, that only one in 10 children relapsed after using the alarm but that with retreatment the child could expect the same chance of becoming dry as those who used the alarm for the first time.

To date, research has been limited on the question of key predictors of outcome. Demographic variables (age, sex, urban/rural, social class) and enuresis classification were unrelated to outcome, similar to that found in previous studies. ${ }^{19}{ }^{24}$ In this study the six months' success rate was significantly lowered by psychiatric disorder in the child, stress in the family, and absence of concern by the child and parents. The addition of urological disorder and developmental delay militated against long term success. While family stress has been reported previously, the link between psychological variables and outcome has been tenuous. ${ }^{19} 25$ Fielding, however, related failure of response to diurnal enuresis, ${ }^{26}$ and Wagner $e t$ al found that children rated by parents as less withdrawn and socially adequate was associated with better outcome. ${ }^{8}$ Surprisingly adverse housing, a factor noted by Dische, ${ }^{19}$ was not related to outcome. This may be due in part to the clinic contacting housing authorities to resolve the situation. The application of a stepwise logistic regression procedure, which enabled factors to be examined independently of each other, resulted in many of the above variables losing significance. The risk score allows prediction of outcome and it is encouraging that a child without adverse variables (table 6) can expect a nine in 10 chance of long term success. The addition of these adverse variables appreciably reduces the chance of success; this is similar to the model of Kolvin et al ${ }^{27}$ with its association between outcome, sex of the child, and absence of psychiatric symptoms.

As an applicability trial this study has demon- strated that enuresis can be managed very effectively in a community based clinic. Treatment should commence with a form of star chart and behavioural procedures because of a reasonable success rate and the absence of side effects. Children failing to respond should be offered the enuresis alarm, but while success ultimately depends on the child's motivation, it is important that its use be supervised and the family receive ongoing encouragement. As a symptom enuresis requires specific treatment but a careful history may reveal a background of additional illness, family stresses, and needs and these too should be resolved to increase the likelihood of a successful outcome.

The authors thank Dr B Herity and Dr L Daly, department of The authirs thanc Dr B Herity and Dr L Daly, department of advice and assistance throughout the study.

1 Foxman B, Valdez RB, Brook RH . Childhood enuresis: prevalence, perceived impact and prescribed treatments. Pediatrics 1986;77:482-7.

2 Devlin JB. Childhood nocturnal enuresis: a descriptive analysis. Ir f Med Sci 1989;158:29.

3 Miller FJW. Children who wet the bed. In: Kolvin I, Mac Keith RC, Meadow SR, eds. Bladder control and enuresis. Clinics in Developmental Medicine No 48/49. Philadelphia: Lippincott, 1973:47-52.

4 Rutter $M$, Yule W, Graham P. Enuresis and behavioural deviance: some epidemiological considerations. In: Kolvin I, MacKeith RC, Meadow SR, eds. Bladder control and enuresis. Clinics in Developmental Medicine No 48/49. Philadelphia: Lippincott, 1973:137-47.

5 Shaffer D, Gardner A, Hedge B. Behaviour and bladder disturbance of enuretic children: a rational classification of a common disorder. Dev Med Child Neurol 1984;26: a comm.

6 Polak HE. More about enuresis. Public Health 1987;101: 185-90.

7 Kolvin I, Taunch J, Currah J, et al. Enuresis: a descriptive analysis and a controlled trial. Dev Med Child Neurol analysis and a

8 Wagner W, Johnson SB, Walker D, et al. A controlled comparison of two treatments for nocturnal enuresis. $\mathfrak{J}$ Pediatr 1982;101:302-7.

9 Netley C, Khanna F, McKendry JBJ, Lovering JS. Effects of different methods of treatment of primary enuresis on psychologic functioning in children. Can Med Assoc $\mathcal{F}$ 1984;131:577-9.

10 Stewart MA. Treatment of bedwetting. FAMA 1975;232: 281-3.

11 Anonymous. Poisoning and enuresis. Br Med f 1979;i:705-6. Cronin AJ, Khalil R, Little TM. Poisoning with tricyclic antidepressants: an avoidable cause of childhood deaths. $\mathrm{Br}$ Med F 1979;i:722.

13 Wille $S$. Comparison of desmopressin and enuresis alarm for nocturnal enuresis. Arch Dis Child 1986;61:30-3.

14 Werry JS, Cohrssen J. Enuresis-an etiologic and therapeutic study. $\mathcal{F}$ Pediatr 1965;67:423-31.

15 Young GC. The problem of enuresis. $B r f$ Hosp Med 1969;2:628-32.

16 O'Hare A. A note on a proposed census based Irish social class scale for epidemiological health research. The Economi and Social Review 1982;13:205-16.

17 Rutter M, Tizard J, Whitmore K. Education health and behaviour. London: Longmans, 1970.

18 American Psychiatric Association. Diagnostic and statistical manual of mental disorders. 3rd Ed. Washington, DC: American Psychiatric Association, 1980.

19 Dische S, Yule W, Corbett J, Hand D. Childhood nocturnal enuresis: factors associated with outcome of treatment with an enuresis alarm. Dev Med Child Neurol 1983;25:67-80.

20 Meadow R. How to use buzzer alarms to cure bed-wetting. $B r$ Med f 1977; ii: 1073-5.

21 Schmitt BD. Nocturnal enuresis: an update on treatment. Pediatr Clin North Am 1982;29:21-36.

22 Goel KM, Thomson RB, Gibb EM, McAinsh TF. Evaluation of nine different types of enuresis alarms. Arch Dis Child of nine different
$1984 ; 59: 748-53$

23 Young GC, Morgan RTT. Reasons for appointment failure among enuretic patients. Community Med 1972;129:23-5.

24 Butler RJ, Brewin CR, Forsythe WI. A comparison of two approaches to the treatment of nocturnal enuresis and the prediction of effectiveness using pre-treatment variables. $\mathcal{J}$ Child Psychol Psychiatry 1988;29:501-9.

25 Butler RJ. Nocturnal enuresis: psychological perspectives. Bristol Wright, 1987.

26 Fielding $\mathrm{D}$. The response of day and night wetting children and children who wet only at night to retention contro training and the enuresis alarm. Behav Res Ther 1980;18: 305-17.

27 Kolvin I, Garside RF, Taunch J, et al. Feature clustering and prediction of improvement in nocturnal enuresis. In Kolvin I, MacKeith RC, Meadow SR, eds. Bladder control and enuresis. Clinics in Developmental Medicine No 48/49. Philadelphia: Lippincott 1973:258-75. 